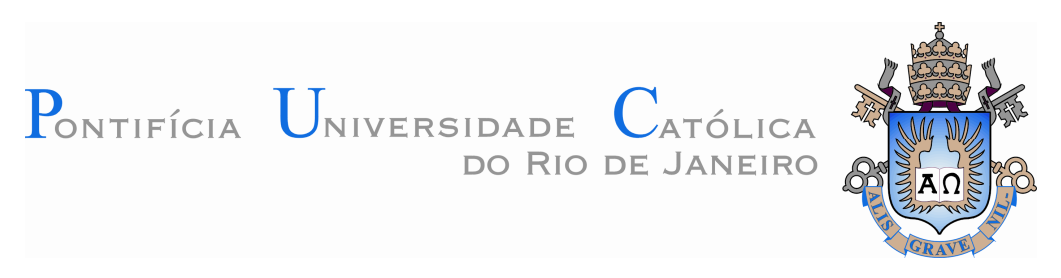

Ana Paula Vieira Peixoto Mauro

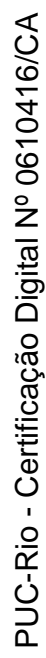

\title{
Design de e-learning: um espaço em construção
}

\section{Dissertação de Mestrado}

Dissertação apresentada como requisito parcial para obtenção do grau de Mestre pelo Programa de Pósgraduação em Design do Departamento de Artes \& Design da PUC-Rio.

Orientadora: Profa. Dra. Rejane Spitz

Rio de Janeiro Agosto de 2008 


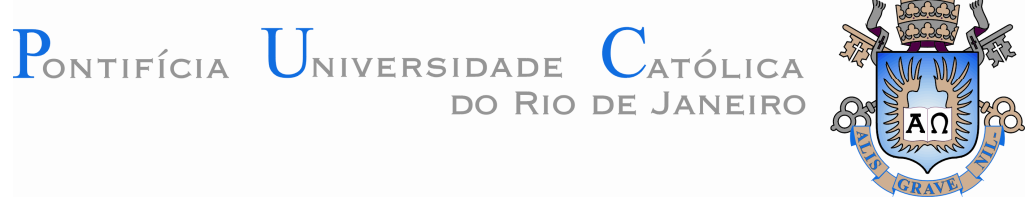

Ana Paula Vieira Peixoto Mauro

Design de e-learning: um espaço em construção

Dissertação apresentada como requisito parcial para obtenção do grau de Mestre pelo Programa de Pós-Graduação em Design do Departamento de Artes \& Design do Centro de Teologia e Ciências Humanas da PUC-Rio. Aprovada pela Comissão Examinadora abaixo assinada.

\author{
Profa. Dra. Rejane Spitz \\ Presidente Orientadora PUC-Rio \\ Profa. Dra. Sophia Roslindo Pimenta \\ Membro - FGV-Rio \\ Profa. Dra. Maria Apparecida Campos Mamede Neves \\ Membro - PUC-Rio \\ Profa. Dra. Rita Maria de Souza Couto \\ Membro - PUC-Rio \\ Prof. Dr. Paulo Fernando Carneiro de Andrade \\ Coordenador Setorial do Centro de \\ Teologia e Ciência Humanas - PUC-Rio
}

Rio de Janeiro, 21 de agosto de 2009 
Todos os direitos reservados. É proibida a reprodução total ou parcial do trabalho sem a autorização da universidade, da autora e do orientador.

\section{Ana Paula Vieira Peixoto Mauro}

Graduou-se em Desenho Industrial, com habilitação em Comunicação Visual pela PUC-Rio em 1994. Atua no planejamento e desenvolvimento de objetos educacionais virtuais desde 1998, quando passou a integrar o programa de educação a distância da Fundação Getulio Vargas, o FGV Online, onde permaneceu até o momento da defesa desta Dissertação.

Ficha Catalográfica

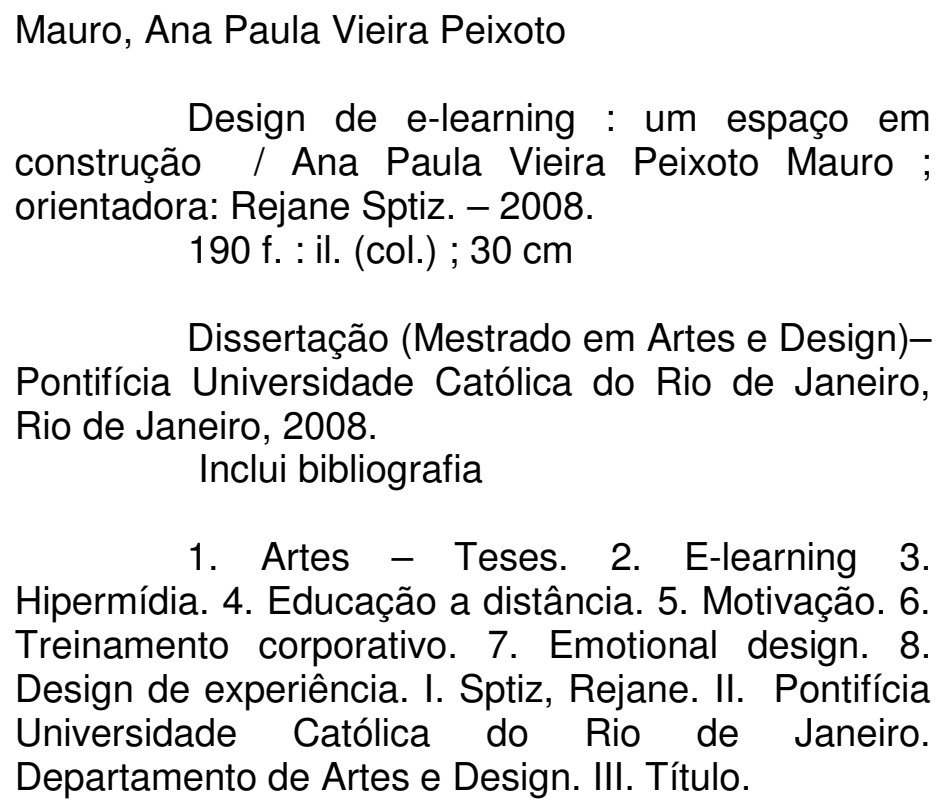

1. Artes - Teses. 2. E-learning 3. Hipermídia. 4. Educação a distância. 5. Motivação. 6. Treinamento corporativo. 7. Emotional design. 8. Design de experiência. I. Sptiz, Rejane. II. Pontifícia Universidade Católica do Rio de Janeiro. Departamento de Artes e Design. III. Título.

CDD: 700 


\section{Agradecimentos}

À CAPES pelo apoio a esta pesquisa.

Ao DAD da PUC-Rio, por ter acreditado neste projeto como uma contribuição aos novos caminhos que o Design vem trilhando.

Ao Programa FGV Online, por toda a estrutura e por ter oferecido as bases de análise a esta pesquisa; em especial à minha coordenadora Sophia Pimenta, por todo o incentivo e carinho.

À Embratur, por ter gentilmente cedido o curso Agente de Viagens Especialista em Brasil para uma análise das contribuições do Design, pelo ponto de vista do engajamento do aluno.

À minha orientadora, Rejane, pela lucidez e sensibilidade com que conduziu meu olhar, chamando limites aos excessos e mostrando caminhos entre as limitações.

Aos membros da Banca, por toda a disponibilidade e respeito dedicados a este trabalho.

Aos colegas de (des)orientação, pelas valiosas contribuições, em especial à amiga Izabella, pela perspectiva sempre alinhada com as tendências mais atualizadas do $e$ learning.

A todos os queridos amigos, sempre tão empenhados na tarefa de suavizar essa laboriosa caminhada; em especial à Bia e à Clarice, por toda a generosidade e amor que uma amizade é capaz de demonstrar.

À minha família - aquela que me mostra de onde vim - pelo incomensurável amor, apoio irrestrito e inabalável crença na minha capacidade; em especial a meus pais, Caetano e Elisabete, por me ensinarem a investir no saber, "pois só ele permanece".

Ao meu marido Cadu - a família que me mostra para onde vou -, por todo o amor, companheirismo, dedicação, compreensão pelas longas e constantes ausências e por me mostrar um futuro em que vale tanto a pena investir. 


\section{Resumo}

Mauro, Ana Paula Vieira Peixoto; Spitz, Rejane. Design de e-learning: um espaço em construção. Rio de Janeiro, 2008. 190 p. Dissertação de Mestrado Departamento de Artes \& Design, Pontifícia Universidade Católica do Rio de Janeiro.

Esta pesquisa discute o papel do designer que atua no desenvolvimento de objetos educacionais virtuais voltados para o treinamento corporativo, inserido em estruturas produtivas de grande porte e com fins lucrativos. Nossa hipótese é a de que o design de e-learning não explora os recursos de hipermídia disponíveis de forma eficiente, em prol do engajamento do aluno. Nosso estudo se estrutura em três partes: primeiramente, dedicamo-nos a entender as estruturas produtivas de empresas com fins lucrativos que desenvolvem o e-learning corporativo e analisamos a atuação do designer nesse contexto. Em um segundo momento, nos debruçamos sobre o potencial oferecido pelo design de hipermídia, a partir das teorias do emotional design e do design de experiência, no sentido de se capturar e de se manter o interesse do usuário aluno. Finalmente, no último capítulo, empreendeu-se um estudo de casos exemplares encontrados na Internet, nos quais identificamos estratégias que visam a promoção de experiências imersivas. A partir dessas características, definimos as categorias que orientaram a análise de um curso a distância, com fins de treinamento corporativo, mediado pela Internet. Concluímos que o designer exerce um importante papel no que tange à usabilidade e ao tratamento informacional dos objetos educacionais virtuais. Entretanto, ao observar-se, por meio da perspectiva oferecida pelas categorias de análise elencadas a aplicação dos recursos utilizados no exemplo do e-learning corporativo, verifica-se que o designer subutiliza o potencial dos recursos de hipermídia hoje disponíveis, os quais poderiam promover um maior grau de envolvimento do aluno com o conteudo educacional apresentado.

\section{Palavras-chave}

E-learning; Hipermídia; Educação a Distância; Motivação; Treinamento Corporativo; Emotional Design; Design de Experiência. 


\section{Abstract}

Mauro, Ana Paula Vieira Peixoto; Spitz, Rejane. Design de e-learning: a space under construction. Rio de Janeiro, 2008. 190 p. Dissertação de Mestrado Departamento de Artes \& Design, Pontifícia Universidade Católica do Rio de Janeiro.

This research discusses the role of the designer that works on the development of virtual educational objects regarding the corporate training, inserted in large size for-profit productive structures. Our hypothesis assumes that the e-learning design does not explore, effectively, the available hypermedia resources, for the student's engagement. Our study id structured in three sections: first, we are dedicated to understanding the productive structures of the for-profit companies that develop the corporate e-learning and we analyze the action of the designer in this context. On a second moment, we debated the potential that hypermedia design offers, from the perspective of the emotional design and the experience design theories, in the sense of capturing and maintaining the user student's attention. Finally, on the last chapter, a study of cases found on the internet was made, in which we identified strategies that look forward the promotion of immersive experiences. Departing from these features, we defined the categories that guide the analysis of a distance course with the purpose of corporate training through the internet. We conclude that the designer plays an important role in what concerns the usability and the informational treatment of the virtual educational objects. Meanwhile, observing, through the perspective offered by the listed categories of analysis, the application of the used resources in the example of the corporate e-learning, it is verified that the designer underuses the potential of the hypermedia resources available nowadays, which could promote a higher degree of involvement of the student with the educational content presented.

\section{Keywords}

E-learning; Hypermedia; Distance Learning; Motivation; Corporative Training; Emotional Design; Experience Design. 


\section{Sumário}

1. Introdução

2. Entendendo os processos produtivos do e-learning 24

2.1. Considerações iniciais 24

2.2. Os cursos customizados, enquanto treinamentos desenvolvidos sob demandas específicas

2.3. Entendendo como se produz um treinamento corporativo, em formato e-learning, desenvolvido sob demanda

2.3.1. Designer Instrucional - aquele que projeta 40

2.3.2. Designer - aquele que traduz visualmente 47

2.4. Reflexões acerca do processo produtivo do e-learning corporativo 55

3. Um novo olhar sobre o design de e-learning 59

3.1. Considerações Iniciais 59

3.2. Diálogos entre design, didática e motivação 62

3.2.1. Aprendizagem significativa 64

3.2.2. Figuras condutoras enquanto estratégia didática freqüente no e-learning

3.3. Novos caminhos para o design de e-learning 69

3.4. Corpo teórico do design de hipermídia enquanto fonte para design de e-learning: diálogos possíveis e desejáveis

3.4.1. Design de Experiência

3.4.2. Emotional Design 82

3.5. Considerações finais 88 
4. Design de hipermídia como parâmetro para aplicações no e-learning: estudo de casos

4.1. Considerações iniciais 95

4.2. Categorias de análise 100

4.2.1. Abordagens introdutórias 102

4.2.2. Representações gráficas de conceitos abstratos 112

4.2.3. Simulações para procedimentos específicos 122

4.2.4. Estrutura Narrativa 133

4.2.5. Integração multimidiática 141

4.3. Estudo de caso do treinamento corporativo via e-learning 147

4.3.1. Entendendo o curso Agente de Viagens Especialista em Brasil 150

4.3.2. Analisando o curso Agente de Viagens Especialista em Brasil em relação à categoria Abordagens Introdutórias

4.3.3. Analisando o curso Agente de Viagens Especialista em Brasil em relação à categoria Representações Gráficas de Conceitos Abstratos

4.3.4. Analisando o curso Agente de Viagens Especialista em Brasil em relação à categoria Simulações para Procedimentos Específicos

4.3.5 - Analisando o curso Agente de Viagens Especialista em Brasil em relação à categoria Estrutura Narrativa

4.3.6. Analisando o curso Agente de Viagens Especialista em Brasil em relação categoria Integração Multimidiática

4.4. Considerações finais 


\section{Lista de figuras}

Figura 1 - Conceito ADDIE. 33

Figura 2 - Exemplo de modelo de produção de um curso on-line customizado, desenvolvido por módulos.

Figura 3 - Exemplo de fluxo de produção de um curso on-line customizado.

Figura 4 - Imagem do material bruto enviado pelo conteudista para o designer instrucional.

Figura 5 - Imagem de tela de storyboard, desenvolvido pelo designer instrucional.

Figura 6 - Imagem da tela seguinte do storyboard, onde se indica a resposta correta da atividade e o seu feedback.

Figura 7 - Exemplo de interface corporativa de curso produzido pelo FGV Online.

Figura 8 - Exemplo de miolo, em curso corporativo produzido pelo FGV Online.

Figura 9 - Exemplo de topo, em curso corporativo produzido pelo FGV Online.

Figura 10 - Exemplo de rodapé, em curso produzido pelo FGV Online

Figura 11 - Exemplo de personagem apresentadora do curso de Matemática, que remete à figura de Einstein.

Figura 12 - Exemplo de personagem apresentadora de um curso voltado para agentes de viagens. O exemplo foi retirado do módulo que trata de Ecoturismo.

Figura 13 - Vista frontal do monumento

Figura 9 - Detalhe da ala oeste do monumento.

Figura 10 - Detalhe do painel 60, da ala oeste do monumento.

Figura 11 - Página inicial do Chemistry Comes Alive!

Figura 12 - Destaque da experiência Mercury Beating Heart.

Figura 13 - Abertura do webdocumentário Who Killed William Robinson?

Figura 14 - Página inicial do webdocumentário Who Killed William Robinson?

Figura 20 - Página inicial do site Sprint Waitless 
Figura 22 - Detalhe do menu de Sprintcuts aberto.

Figura 15 - Primeira tela da atividade "Ajuste a curva" acompanhada de sua explicação.

Figura 16 - Primeira tela da atividade "Reproduza as figuras" acompanhada de sua explicação.

Figura 25 - Comparação entre os gráficos que demonstram a emissão de gás carbônico (vermelho, posição superior) e a temperatura na terra (azul, posição inferior).

Figura 17 - Demonstração do gráfico desde o aumento da emissão de $\mathrm{CO}_{2}$ (em vermelho) na Terra.

Figura 18 - Para alcançar a representação gráfica do ponto atual de concentração de $\mathrm{CO}_{2}$, Al Gore sobe em uma grua.

Figura 19 - Destaque do ponto "Concentração de $\mathrm{CO}_{2}$ atual".

Figura 20 - Para alcançar a representação gráfica da projeção de concentração de $\mathrm{CO}_{2}$ na atmosfera terrestre, mantendo o ritmo de emissão atual, daqui a 50 anos, Al Gore tem de subir ainda mais a grua.

Figura 30 - Imagem por nós clareada e destacada na "área extra", criada para a projeção do suposto índice concentração de $\mathrm{CO}_{2}$, após 50 anos de queima irrestrita de combustível fóssil.

Figura 31 - Destaque do ponto "Concentração projetada depois de mais 50 anos de queima irrestrita de combustível fóssil".

Figura 32 - Após baixar a grua, Al Gore destaca a desproporção entre sua altura e o ponto de projeção para dali a 50 anos.

Figura 21 - Página inicial do Virtual Knee Surgery. Recepção da clínica.

Figura 22 - Início da cirurgia de joelho. Ambiente hospitalar.

Figura 23 - Mapa de atividades, acessível pelo botão disponível ao longo de todo o objeto, no canto superior direito.

Figura 24 - Destaque da ficha com os sinais vitais de uma pessoa saudável em comparação com a ficha da paciente para a decisão do usuário se esta apresenta ou não condições de ser operada.

Figura 25 - Detalhe da tela de interação que solicita que o aluno decida qual dos dois joelhos da paciente necessita de intervenção cirúrgica. 
Figura 26 - Primeiro momento de simulação. Um menu de instrumentos é apresentado e a caixa da ordem de interação convida a escolher especificamente a ferramenta "marcador" (marker).

Figura 27 - Exemplo de ação cuja finalização é validada pelo próprio objeto, permitindo o avanço automático do usuário. Só depois que o usuário aparar as 5 calosidades apontadas pelas setas, ele seguirá adiante na seqüência.

Figura 40 - Detalhe de ação do usuário marcando linhas perpendiculares, para criar referências no momento da sutura.

Figura 41 - Detalhe de ação do usuário realizando a incisão dentro de um eixo pré-concebido, que não permite deslizes em direções erradas.

Figuras 42 a 50 - Seqüência de quadros que mostra o vídeo do site Sprint Waitless que ensina "Como descascar rapidamente uma batata".

Figuras 51 a 54 - Seqüência de quadros que mostra o vídeo do site Sprint Waitless que ensina "Como descascar rapidamente uma banana.

Figura 55 - Detalhe do vídeo - "Vamos tentar... Segure firme ("hold fiiiiiirmly') a banana com as duas mãos."

Figura 56 - "Divida a banana na metade". Detalhe do grafismo que indica o movimento de separação das duas metades.

Figura 57 - "Esprema ('squeeeeeeeze) cada metade com uma mão". Início dos gráficos animados que mostra a forma de espremer o conteúdo da banana.

Figura 58 - Detalhe do fim da animação mostrando que o conteúdo deve ser espremido de fora para dentro.

Figuras 59 a 60 - Encerramento do vídeo

Figura 28 - Página que resume as condições do assassinato de William Robinson.

Figura 29 - Página com links para algumas correspondências que fornecem interpretações da época sobre os crimes.

Figura 30 - Captura de detalhe da página inicial do Microsoft Dynamics - as personagens fazem as vezes de diferentes perfis de usuário para o software. Os atores que os representam mantêm-se em constante movimento até que se clique em um deles para ouvir seu discurso.

Figuras 64 a 66 - Momentos da apresentação do Microsoft Dynamics 
Figuras 67 e 68 - Momentos da apresentação do Microsoft Dynamics

Figura 69 - Exemplo da tela de introdução de um estudo de caso. Em destaque, SIEMENS: Creating a high performance culture.

Figura 70 - Página do site Sprint Waitless, onde se permite o disparo para celulares e caixas postais eletrônicas os vídeos de simulação.

Figuras 71 a 74 - Diferentes momentos das personagens apresentadoras do curso Agente de Viagens Especialista em Brasil.

154

Figura 75 - Exemplo de tela do módulo Conheça nossos Produtos Turísticos com as principais opções de navegação.

Figura 76 - Detalhe dos botões da barra de navegação em destaque. 156

Figura 77 - Detalhe dos botões que levam a janelas pop-up com destaque das localidades.

Figuras 78 a 81 -Diferentes tipos de hipertextos disparados pelo curso Agente de Viagens Especialista em Brasil

Figuras 82 a 85 -Momentos da abertura do curso Agente de Viagens Especialista em Brasil.

Figuras 86 a 90 - Telas de abertura dos módulos 1, 2 e 3 do curso Agente de Viagens Especialista em Brasil.

Figura 91 - Tela onde são apresentados os diferentes fuso-horários nas diferentes áreas do Brasil.

Figura 92 - Tela com os botões que explicam os diversos tipos de ligação telefônica.

Figura 93 - Tela com a janela pop-up onde se explica como realizar uma ligação para outro país. 


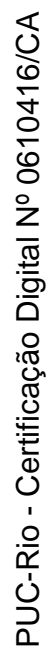

Sempre é pouco, quando não é demais.

Arnaldo Antunes 